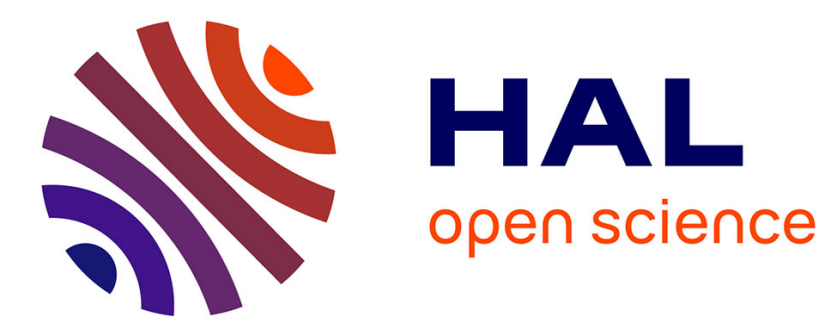

\title{
Product Usage in Engineering Design
}

\author{
Xiaoguang Sun, Rémy Houssin, Jean Renaud, Mickaël Gardoni
}

\section{To cite this version:}

Xiaoguang Sun, Rémy Houssin, Jean Renaud, Mickaël Gardoni. Product Usage in Engineering Design. 12th IFIP International Conference on Product Lifecycle Management (PLM), Oct 2015, Doha, Qatar. pp.790-799, 10.1007/978-3-319-33111-9_72 . hal-01377508

\section{HAL Id: hal-01377508 \\ https://hal.inria.fr/hal-01377508}

Submitted on 7 Oct 2016

HAL is a multi-disciplinary open access archive for the deposit and dissemination of scientific research documents, whether they are published or not. The documents may come from teaching and research institutions in France or abroad, or from public or private research centers.
L'archive ouverte pluridisciplinaire HAL, est destinée au dépôt et à la diffusion de documents scientifiques de niveau recherche, publiés ou non, émanant des établissements d'enseignement et de recherche français ou étrangers, des laboratoires publics ou privés. 


\title{
Product Usage in Engineering Design
}

\author{
Xiaoguang Sun ${ }^{1}$, Rémy Houssin ${ }^{1,2}$, Jean Renaud ${ }^{1}$, Mickaël Gardoni ${ }^{1,3}$ \\ ${ }^{1}$ INSA of Strasbourg, LGECO, 24 bd de la Victoire, 67084 Strasbourg Cedex, France \\ xiaoguang.sun@insa-strasbourg.fr ; jean.Renaud@insa-strasbourg.fr \\ ${ }^{2}$ University of Strasbourg, 3-5 rue de l'Université, 67000 Strasbourg, France \\ rémy.Houssin@unistra.fr \\ 3'ÉTS / LIPPS, Montréal, H3C 1K3, Québec, Canada \\ mickael.gardoni@etsmtl.ca
}

\begin{abstract}
This paper mainly focuses on improving the product performance by taking user factors into consideration during the design phase. Firstly, the impact of design modification on the product lifecycle and the importance of the user in the engineering design process is discussed. Secondly, some reasons of why simply carrying out a socio-technical analysis hardly work on changing the design result are explained, what kinds of the data should be concerned by designer and how to collect data are discussed. Last, some helpful methods are introduced. Considering the costs of modifications are usually very expensive and it may make the product (system) more complex, a novel idea is proposed, which to generate a user manual by analyzing the interaction between product behaviour and user behaviour to help designer to minimize the possibility of design modification after prototyping phase.
\end{abstract}

Keywords: design process, socio-technical, user, product (system) performance.

\section{Introduction}

Most mechanical engineering designs can be defined as an innovative and highly iterative process involve designer's personal resources of creativeness, communicative ability, and problem solving skill [1]. Despite the engineering design is already a fairly mature field, design modification that occurs after prototyping phase remains a troublesome issue. Design modification, that can be understood as to change the product or some related documents when these in the issued state, is an essential and routine activity in the whole product lifecycle. This alteration is attributable to various uncertain factors, e.g. market changes, the inaccurate of the product positioning, the incomplete customer and user requirements analysis, the imperfection of the product development means and support tools, etc. [2], as is showed in Fig. 1. Over the years, the global marketplace has fostered the need to develop new products at a very rapid and accelerating pace and there is a continuous requirements for new, cost-effective, high-quality products. Therefore, designer must 
be very efficient in the design process. Taking too long to bring product into market, costing too much, or inconsiderate are the result of a poor design process [3]. In general, the impact of early design alteration on the whole product lifecycle is less than the late change and the cost of the design modification will increase over time [2]. Therefore, reducing the design modification is significant to the entire product lifecycle.

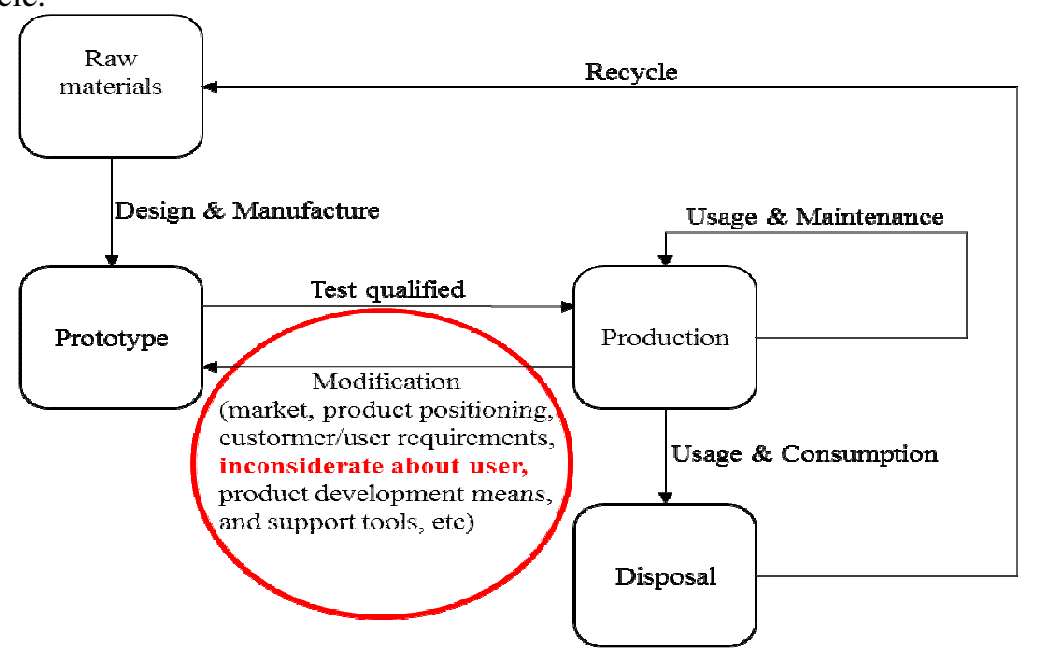

Fig. 1. Design modification in the product lifecycle

In order to shorten the design cycle, reduce the design alteration and the costs of the design, a group of researchers have focused their efforts on it and some well-established engineering design approaches have been developed. Certain techniques can be adapted to fulfill the requirements during the design process, however most current technical approaches stagnate at the functional level, without analyzing the behaviour of the overall system (system, user). Although, Industry and academia generally acknowledge that human aspect is crucial for the success of the product, there are few practicable approaches for designers concerning these factors in the synthesis part of the design works [4]. It is also one of the primary reasons that the design modification is required after prototyping phase. This paper primarily focuses on improving the product performance by decreasing the design modification that occurs after the prototyping stage during the design phase from the user's perspective.

\section{Product usage in engineering design}

In the beginning, a design problem always commences as a fuzzy, abstract idea in the mind of the designer. When designer starts to design a product, the product itself is unknown, but what designer wants it to do is known. It means that designer needs to transform not only the customer requirements, but also the user requirements to the product performance, as is showed in Fig. 2. 


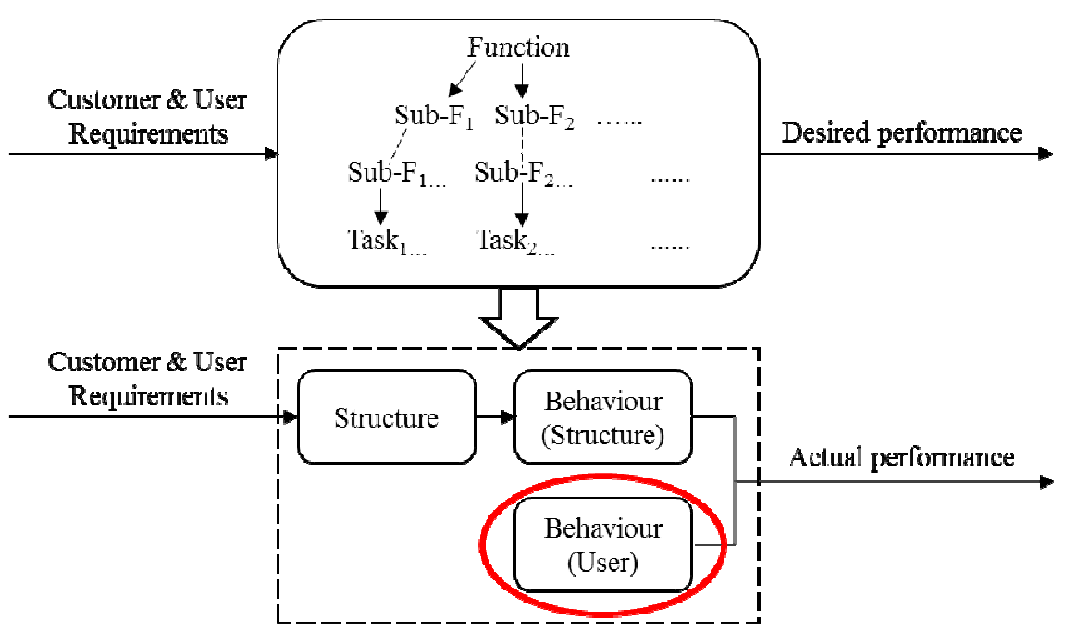

Fig. 2. Function, Task, Structure and Behaviour

Behaviour can be considered as the actual output, reflects the physical properties of the system, however, function is only a desire [3]. The function can be defined as to fulfill the customer requirements and express the purposes of the production system (product). A product's (system's) function, usually, can be divided into many sub-functions, and each sub-function may be subdivided. Each sub-function can be fulfilled by a task. The structure can be considered as the elements of the product who realize technical tasks. And the user realizes the socio-technical task to fulfill the manual functions. The behaviour can be perceived as a characteristic of the structure and/or user which can be directly derived from tasks done by the structure and/or user. In fact, a common problem what most designer confronted is that there may be a gap between desired performance and real performance. For example, a new product (system) is designed in accordance with customer's willingness to state an organized object that works reliably and efficiently. However, when design finished, the prototype may not run as efficiently as expected, even some dangerous phenomena may be generated, the users might feel it difficult to support the way that they work, while the human-machine interface may provide a poor match with the needs of the task [5]. Because the design process is very complex, especially for a complex product (system), one of the main contributory factor of product (system) performance is human aspects. However, it is hard for designer to take all factors and situations (structure, user) into consideration during the design phase.

This part is organized as follows. In section 2.1, the importance of the end user in the engineering design is stated, and then, in section 2.2 , by reviewing the existing job, the reason of why simply carrying out a socio-technical analysis hardly work on changing the result of design after some fundamental decisions is presented. In section 2.3 and 2.4, some useful suggestions for integrating socio-technical factors into design process are discussed. 


\subsection{Sociotechnical aspects or factors}

Design activity always begins with addressing the whole user experience [6]. User and their experience play an increasingly prominent role in the design process, Redström [7] argued that a main obligation of poor design is a matter of insufficient knowledge about the end user, their capacities and requirements and desires. He also confirmed that design activity should be based on improving such knowledge. Fernandez [8] held that it will lead to a positive influence of productivity, health and safety of users, job satisfaction if human being's physical, physiological, biomechanical, and psychological capabilities could be taken into account in the design phase and offered a good implementation. Most products (systems) run with human being in some principle.

It is often considered from economic and social goals point of view that design is considered as both a technical and a sociotechnical activity [9, 10]. Here, in engineering design process, sociotechnical issues from human refer to physical, mental, and sensory factor. Technical problems could be defined as some certain technical functions in the functional analysis, and then, designer could find out the technical solutions to achieve it. However, it is seldom that socio-technical considerations are integrated successfully into the planning processes in practice.

\subsection{Integrating sociotechnical factors into design process}

A failure to deal with the social requirements may result in a poor design [5]. Human factor in engineering is the study of interaction between user and the machine. A successful design solution demands the design fits all the people using it. Many researchers engaged in socio-technical systems for a long time. In order to design a combine harvester seat to maximize the match seat dimension for Iranian operators, Ghaderi et al. [11] obtain the data of 476 combine Iranian operators and select 200 data randomly as a sample to propose combine harvester seat dimension based on anthropometric principles. Dul et al. [12] recommended that designer could adopt the existing ISO and CEN standards on ergonomics to improve human well-being and overall system performance. Design process is systemic, interactive, and iterative. Houssin et al. [13] argued that user safety information should be integrate in all phase by building the working situation model to improve the product performance in the use situations.

Despite the sociotechnical systems have been studied for many years, poor designs are still existed. It seems that simply carrying out a sociotechnical analysis could not change the result of design after some fundamental decisions have been made. Some reasons are (1) an over system concept could be built without considering the difficulty or the complexity in realizing the technical design that may impact the user experience. (2) Different level of the modification of the new system may affect the users and existing procedures. (3) It usually lays down system requirements and conducts a phased development with limited time for feedback. (4) Since human factors experts has been employed to estimate on a prototype, it is still impossible to solve all problems that designer have identified. (5) The current design is not 
involving enough user types in the design process and realizing the interaction between system and user. Where, user involving in design process is a real organization problem. If user intervenes early in the design process designer could limit solution set. Otherwise, some expensive modifications may be generated when user requirement needs to change at the later design stage.

This may lead to the product (system) not run as efficiently as intended. Although these continuing problems, Maguire [5] and SUN et al. [4] suggested that designer could realize the optimization (high quality) system by carrying out a sociotechnical system method in a particular environment where the advantage of the approach can be achieved. For example, (1) building upon a more modest system concept after user feedback. (2) Taking agile systems approach to develop more continual iterations of the system in consultation with users, and allow the user requirements changing and specified functions being modified before the development of the next system version. (3) Recruiting a wide range of users to influence the fundamental design concept.

\subsection{User data collection}

From the discussion above, the information about sociotechnical include numerous human physical, mental, and sensory factors. The difficulty in design process to take human factor into account is the abundance of anthropometric data and some unpredictable situations. Current practices of ergonomics analysis are mainly about human posture and motion [14]. It guides system (product) design that will improve user's safety [13], comfort, and performance [4] and also provide a consideration of service and disassembly recycle for product [15]. However, what kinds of information would be of interest or useful to designers and engineers? The features of this information [14] should be of (1) various anthropometric data sets and disparate groups ; (2) a range of protective device, such as gloves, and helmets, etc.; (3) predictive ability about strength and stamina of different demographic when doing a task; (4) simulation ability that could emulate actual movements and postures with less input descriptions in all physically conditions; (5) providing hand grip, strength and visual sight lines with and without mirrors and obstructions; (6) being capable of task timeline analyses; (7) performing reach and fit analyses in all situations; and (8) transmitting data and/or carrying out I/O commands well in different computer aided design (CAD) systems usually involved in rendering and specifying products, tools, and workstations.

An existing problem is that the increasing mental workload during the process of the human-machine interaction may lead user feel tired and difficult to support the way they work. Naderpour et al. [16] argued that cognitive user knowledge (situation awareness, SA) in the running process of product support systems to improve product (system) performance and decrease failure rate. Although many researches have stated that machine learning techniques could be useful for situation evaluation, when these intelligent techniques deployed in practice, they are very limited as a consequence of the lack of suitable training data [17].

The manner of the data collection is also important because it may influence the choice of methods used for user requirement analysis [15]. Data collection could 
comply with some design principles, such as sociotechnical meta-principles $[18,19]$ that design is systemic, all parts of a system are interrelated, and that values and mindsets are indispensable to design.

\subsection{Design approaches from user's perspective}

To date, many existing jobs make an effort to develop a model to predict whether or not a design will be viewed by user as comfortable [20]. Some typical methods for predictive modeling of human motions have been summarized by Chaffin [14]. Undoubtedly, digital human models (DHM) has received the most attention, these models are capable of serving as effective ergonomics analysis and design methods and required for virtual environment for the exploration and manufacturing designs from an ergonomic perspective [14, 15, 21, 22]. The most crucial characteristic of the DHM is that it allowed designer to discover potential problem and through the use of DHM to emulate human ability, requirement and performance could save a great deal of time and money in design and prototype testing[14]. However, it also exists several limitations in this method. For instance, the simulation must on the basis of real human motion data, it will take a lot of time and energy to collect data from disparate group. There are still some others studies perceive that human mental and sensor are also crucial factors improving performance and reducing errors. Naderpour et al. [16] developed an abnormal situation modeling (ASM) to decrease operator's load of work, mental stress and the error rates that consequent in the process of dealing with abnormal situations (highly complicated and exhausting mental activities). This method also has some limitations. Updating knowledge is difficult when new information need to be added. It offers only an estimate of user behaviour in the process. SUN et al. [4] propose a behavioural design approach to help designers find out potentially hazardous phenomena and zones of the product (system) during the design stage by taking user conditions and requirements into consideration. A behavioural design approach (BDA) software was developed as a simple case to valid the applicability of this method. However, there are still many problems demanding further research. Such as, how to categorize disparate users, e.g. specialists, experienced, "normal" users and newcomers, how could the designer acquire more knowledge of the user, and so on. Due to the final operator of product is user not the customer, we propose that developer and designer can develop a knowledge base in the initial design stage not only for customer, but also for user. Beyond the customer and user requirements, this type of database should include various information about user such as user's gender, age, region, experience, etc.

\section{The case study}

In consideration of when modifications are required after the prototyping phase, the costs of modifications are usually very expensive and the modifications often take the shape of adding equipment and procedures that may impact the product (system) 
performance. Normally, a product and a user manual are provided to the customer, and the product is usually paid more attention than the user manual. A user manual is usually created as a user guide at the last phase of product development for the purpose of giving assistance to operator using a specific system or product. Actually, a good user manual not only can help user to use the product in a right and an efficient way, but also can help enterprise to save a large amount of cost of staff training and customer service. Now, we propose to generate user manual not at the last phase of product development but during the design phase to guide the design process.

Herein, we just take a simple example to explain the design deficiency of one kind of clip (Fig.3) that result from the inconsideration of user factors. We take this example to show that even for simple product the usage aspects influence the performance of product. So for more complex product the problem is more influencing. We often encounter such a problem: when we take notes in class or lecture, the book will be automatically turn back or closed if we do not fix the book with our elbow or some other things. To solve this problem, it is better for us to use a clip.

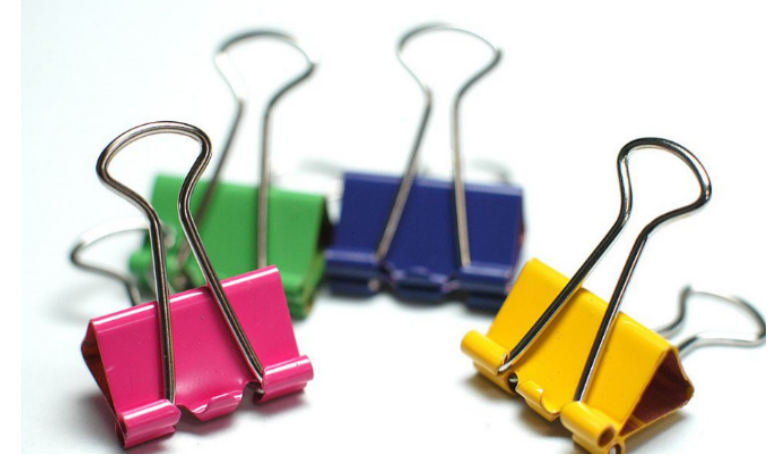

Fig. 3. The clip

First of all, we should know how to use a clip. It takes three steps: 1) transfer to the treatment area; 2) Open the clip; 3) close the clip. Then, by using functional analysis we identified the sub-functions of this Clip. We used also the behavioural design approach proposed by SUN [4] to identify each task necessary to fulfill all functions and their nature. (Table 1).

Table 1. Function Behavioural Analysis

\begin{tabular}{|c|c|c|}
\hline Function & Tasks & Task nature \\
\hline \multirow{2}{*}{$\begin{array}{l}\text { F1 (Receiving the } \\
\text { book) }\end{array}$} & T11: Receiving & Socio-technical \\
\hline & T12: Transferring to the treatment area & Socio-technical \\
\hline \multirow{5}{*}{ F2 (Fixing the book) } & T21: Receiving & Socio-technical \\
\hline & T22: Transferring to the treatment area & Socio-technical \\
\hline & T23: Open the clip & Socio-technical \\
\hline & T24: Release the fingers & Socio-technical \\
\hline & T25: Fix the book & Technical \\
\hline
\end{tabular}


The approach proposed by SUN [4] is constituted in the 7 following steps:

1. Dividing function into two parts. The first is the technical function realized by technical solutions; the second is the manual function fulfilled by the user.

2. Finding the necessary structure to carry out the technical function.

3. Obtaining the behaviour of structure tasks (operation, motion, etc.) that the structure has to perform to achieve the function.

4. Identifying and studying the tasks performed by the user to fulfil manual functions.

5. Analysing the interaction between the structure's behaviour and the user's behaviour.

6. If the global behaviour meets the performance criteria (functionality, productivity, safety, cost, quality, etc.), designers can continue to develop the system.

7. Where the interaction between the user's behaviour and that of the structure does not ensure the needed performance, designer have to do some modifications. Designer can change user's tasks, or go back to the structure level to modify the structure or go back to the function level to modify or change the function decomposition.

As a result, we analyzed the interaction between product behaviour and user behaviour (Fig. 4) to find out the potential problems.
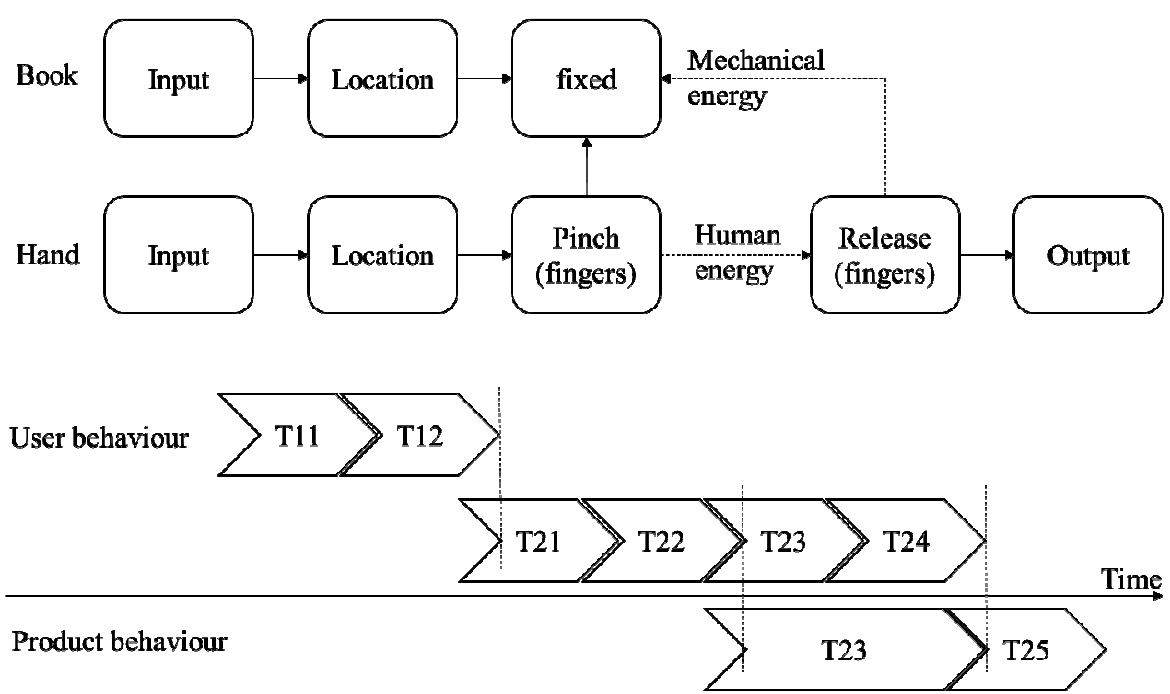

Fig. 4. The behavioural analysis

During the T23, in consideration of the age and the gender of the user, it may be difficult for a young girl in the primary schools to open this type of clip cause that young girls are usually not strong enough.

During the T24, the user locate the position of the book and release the clip, it is dangerous that the finger might be caught in the clip. 
During the T25, when the book is fixed, due to the clip is too light the book may close.

From this simple case, we can find some design deficiencies and could be avoided if the user behaviour could be considered during the design stage, some modification after prototyping phase also be avoided. Behavioural design approach could help designer to find out the potential problems and determinate all tasks required to use the product. Consequently, a user manual can be generated from these tasks before the prototyping phase. By using the behavioural design approach during the design phase, designer can carry out design activities and propose its user manual simultaneously. In this case, a user manual will educate not only user how to use the product (system) but also design activities to avoid the potential problems. In traditional approaches, these problems may require some expensive modifications to be solved because the prototype is already designed. By using the behavioural design approach, generation user manual allows designer to identify the potential problems before constructing the prototype and avoid the costs of the modifications.

\section{Conclusion and future work}

In this paper, we have presented the impact of design modification on the product lifecycle and discussed the importance of the user in the engineering design process. From the existing studies, we find that one of the primary reasons of the design modification occurs after prototyping phase is that the designer fails to fully take the socio-technical factors into consideration during design process. By reviewing the existing approach of integrating socio-technical factors into design process, we also realize that the difficulty in design process to take human factor into account is that the abundance of anthropometric data and some unpredictable situations of user operation. Although the case that we present is very simple, it still exists some design deficiencies that result from the inconsideration of user factor.Usually, a user manual generated after the prototyping phase to guide user how to operate the product (system). Now, we suppose that to create the user manual by analyzing the interaction between product behaviour and user behaviour to direct the design activities during the early design stage. In this way, designer could minimize the possibility of design modification after prototyping phase, thereby reducing the costs of the design and shortening the design cycle.

\section{References}

1. Budynas-Nisbett. Shigley's Mechanical Engineering Design, Eighth Edition. McGraw-Hill, New York, (2006)

2. WAN L, GUO G, DAI H. Realization of Engineering Change in PLM System. Journal of Chongqing University (Natural Science Edition), 28(1), 112-115, (2003)

3. David G. Ullman. The Mechanical Design Process, Fourth Edition. McGraw-Hill, New York, (2010) 
4. Huichao SUN, Rémy Houssin, Mickael Gardoni, François de Bauvrond. Integration of user behaviour and product behaviour during the de sign phase: Software for behavioural design approach. International Journal of Industrial Ergonomics, 43(1), 100-114, (2013)

5. Martin Maguire. Socio-technical systems and interaction design-21st century relevance. Applied Ergonomics 45(2), 162-170, (2014)

6. Francesco Pucillo, Gaetano Cascini. A framework for user experience, needs and affordances. Design Studies 35(2), 160-179, (2014)

7. Johan Redström. Towards user design? On the shift from object to user as the subject of design. Design Studies. 27(2), 123-139, (2006)

8. Jeffrey E. Fernandez. Ergonomics in the workplace. Facilities 13(4), 20-27, (1995)

9. Huichao SUN. Improving product performance by integration use tasks during the design phase: a behavioural design approach. LGECO, INSA de Strasbourg, (2012)

10. Per Langaa Jensen. Human factors and ergonomics in the planning of production. International Journal of Industrial Ergonomics 29(3), 121-131, (2002)

11. Edris Ghaderi, Ali Maleki, Iman Dianat. Design of combine harvester seat based on anthropometric data of Iranian operators. International Journal of Industrial Ergonomics 44 (6), 810-816, (2014)

12. Jan Dul, Henk de Vries, Sandra Verschoof, Wietske Eveleens, Albert Feilzer. Combining economic and social goals in the design of production systems by using ergonomics standards. Computers \& Industrial Engineering 47(2), 207-222, (2004)

13. R. Houssin, A. Coulibaly. An approach to solve contradiction problems for the safety integration in innovative design process. Computers in Industry, 62(4), 398-406, (2011)

14. Chaffin D B. Improving digital human modelling for proactive ergonomics in design. Ergonomics, 48(5), 478-491, (2005)

15. Julian Faraway, Matthew P. Reed. Statistics for Digital Human Motion Modeling in Ergonomics. Technometrics, 49(3), 277-290, (2007)

16. Mohsen Naderpour, Jie Lu, Guangquan Zhang. An abnormal situation modeling method to assist operators in safety-critical systems. Reliability Engineering and System Safety 133, 33-47, (2015)

17. N.G. Brannon, J.E. Seiffertt, T.J. Draelos, D.C. Wunsch II. Coordinated machine learning and decision support for situation awareness. Neural Networks. 22(3), 316-25, (2009)

18. Chris W. Clegg. Sociotechnical principles for system design. Applied Ergonomics, 31(5), 463-477, (2000)

19. Sian Christina, Patrick Waterson, Andrew Dainty, Kevin Daniels. A socio-technical approach to improving retail energy efficiency behaviours. Applied Ergonomics 47, 324-335, (2015)

20. Kolich M, Taboun S.M. Ergonomics modelling and evaluation of automobile seat comfort. Ergonomics, 47(8), 841-863, (2004)

21. Jung, K., Kwon, O., \& You, H. Development of a digital human model generation method for ergonomic design in virtual environment. International Journal of Industrial Ergonomics, 39(5), 744-748, (2009)

22. Magistris G D, Micaelli A, Savin J, et al. Dynamic digital human models for ergonomic analysis based on humanoid robotics techniques. International Journal of the Digital Human, 1(1), 81-109, (2015) 